УДК 517.9; 004; 551.58

\title{
ИССЛЕДОВАНИЕ ИЗМЕНЕНИЙ ГЛОБАЛЬНОГО КЛИМАТА С ИСПОЛЬЗОВАНИЕМ ВЕЙВЛЕТНЫХ ФАЗО-ЧАСТОТНЫХ ФУНКЦИЙ, ФАЗО-ЧАСТОТНЫХ И ФАЗО-ВРЕМЕННЫХ ХАРАКТЕРИСТИК ГЕЛОКОСМИЧЕСКИХ И КЛИМАТИЧЕСКИХ ПЕРЕМЕННЫХ. ЧАСТЬ 2
}

\author{
Алексеев Валерий Иванович, \\ v_alekseev@ugrasu.ru
}

Югорский государственный университет, Россия, 628012, г. Ханты-Мансийск, ул. Чехова, 16.

\begin{abstract}
Актуальность исследования обусловлена необходимостью установления истинных причин и закономерностей изменений глобального климата на Земле.

Цель: применить разработанный в первой части статьи метод анализа изменений климата с вычислением временных вейвлетных фазо-частотных функций, фразо-частотных и фазо-временных характеристик переменных с использованием непрерывных вейвлетных преобразований для установления закономерностей изменений глобального климата; в частности, согласованности изменений гелиокосмических переменных с самоорганизованными Тихоокеанским декадным, Североатлантическим и Южным/Эль-Ниньо колебаниями, изменениями озонового слоя в стратосфере и потеплением в Арктической зоне России, тектоническими процессами Земли.
\end{abstract}

Объекты: временные ряды изменений гелиокосмических и климатических переменных, индексы Североатлантического и Южного/Эль-Ниньо колебаний, Тихоокеанского декадного колебания, ряды изменений тектонических процессов Земли, ряды изменений озонового стоя в стратосфере и температуры воздуха в Арктике.

Mетоды: непрерывное прямое вейвлет-преобразование исходных данных с использованием комплексного вейвлета 'cgaи5' с вычислением временных вейвлетных фазо-частотных функций, фазо-частотных и фразо-временных характеристик переменных кластерный анализ; оценка и анализ плотностей распределений фазо-временных характеристик; оценка и анализ коэфффициентов корреляций между фразо-частотными и фразо-временными характеристиками переменных в равных интервалах времени.

Результаты. Вычислением матриц корреляций между вейвлетными фразо-частотными характеристиками переменных, построением совместных графиков фразо-частотных и фразо-временных характеристик этих же переменных в заданных интервалах времени получено, что изменения гелиокосмических переменных, солнечной активности, вулканических извержений Земли, концентрации в атмосфрере двуокиси углерода $\mathrm{CO}_{2}$, озонового слоя в стратоссрере, землетрясений, цунами и природных катастрофр, изменения скорости вращения Земли и продолжительности земных суток принадлежат к одному классу изменчивостей переменных. Эти изменчивости обусловлены изменениями расстояния Солнца от барицентра. Установлена тесная взаимосвязь между колебательными процессами гелиокосмических переменных, солнечной активности и вулканических процессов на Земле, изменений концентрации двуокиси уәлерода $\mathrm{CO}_{2}$ в атмоссрере с самоорганизованными процессами Североатлантического, Тихоокеанского и Южного колебаний/Эль-Ниньо, связанная с изменениями скорости вращения Земли и продолжительности земных суток. Обосновано, что рост вулканической деятельности Земли в современности приводит к снижению озонового слоя в стратосфере, усилению солнечной радиации и росту приземной температуры. В особенности эти процессы сильно проявляются в Арктической зоне России. Показано, что изменения приземной температуры на Земле обусловлены изменениями солнечной активности, парниковым эфффектом, изменениями теплосодержания океана и температуры воздуха над сушей и океаном. Построение изображений временных вейвлетных фазо-частотных фрункций фразовременных характеристик переменных позволяет визуализировать историю изменений переменных во времени и в фразочастотной области и прогнозировать эти изменения на некоторый временной горизонт на характерных частотах.

\section{Ключевые слова:}

Глобальное изменение климата, непрерывное прямое вейвлет-преобразование, временная вейвлетная фазо-частотная фуункция, вейвлетная фразо-частотная и фразо-временная характеристики, коэфффициенты корреляций, озоновый слой, потепление в Арктике, тектонические процессы в недрах Земли, океанические самоорганизованные колебания.

Представляет интерес изучение закономерностей взаимосвязанных изменений гелиокосмических и климатических переменных с использованием метода анализа данных, разработанного в первой части статьи автора.

Цель исследования: разработка метода, позволяющего установить закономерности изменений глобального климата в прошлом и в современности и причины этих изменений с вычислением временных вейвлетных фазо-частотных функций, фазо-частотных и фазо-временных характеристик переменных.

\section{Исходные данные}

Решение задачи производится анализом гелиокосмических и климатических факторов, влияющих на природные процессы Земли [1-3]. В качестве таких факторов использованы графики, приведенные на рис. 1 в первой части работы, а также графики переменных, приведенных на рис. 1.

Сравнительное исследование относительных изменений гелиокосмических и климатических переменных Земли в интервале времени 1656.5-2009 гг.

На рис. 2 представлены графики изменений вейвлетных фазо-частотных и фазо-временных характеристик гелиокосмических и климатических переменных $\varphi_{f_{i}}(a, \bar{b}) \varphi_{f_{i}}(\bar{a}, b), i=1,5,11,15,16$ при значениях масштаба $a(1: 1000)$ вейвлета 'cgau5'. Особенностями изменений этих кривых на рис. 2 является то, что эти группы переменных, за исключением $\varphi_{f_{15}}(a, b)$, относятся к одному классу, разбросы изме- 
нений этих переменных относительно друг друга в наблюдаемом интервале времени небольшие; коэффициенты корреляций $r$ между переменными $\varphi_{f}(a, \bar{b})$ для этих функций в 1955-2006 гг. по табл. 2 в первой части статьи находятся в интервале $0,84 \leq r \leq 0,94$. Это означает, что в изменениях гелиокосмической переменной $f_{1}$, солнечной активности $f_{5}$ и земных климатических переменных $f_{11}$ и $f_{16}$ существует согласованная тесная связь в изменениях фазочастотных и фазо-временных характеристик. Изменения переменной $f_{1}$ обуславливает изменения $f_{5}$ и $f_{11}$; в свою очередь, вулканизм на Земле $f_{11}$ обуславливает изменение концентрации $\mathrm{CO}_{2} f_{16}$ в атмосфере Земли. Изменения переменной $f_{15}$ - приземной температуры, отличаются от изменений, $f_{1}, f_{5}, f_{11}, f_{16}$, ее изменения обусловлены другими причинами. На изменения приземной температуры $f_{15}$, кроме влияний $f_{5}, f_{11}$ и $f_{16}$, как показано в табл. 2 в первой части статьи, существенно влияют изменения температур толщ вод морей и океанов, температура воздуха над сушей и над океаном в экваториальной зоне. На рис. 2, $b$ приведены графики изменений вейвлетных фазо-временных ха$\left.{ }^{15}\right] 10^{22}$ TभC

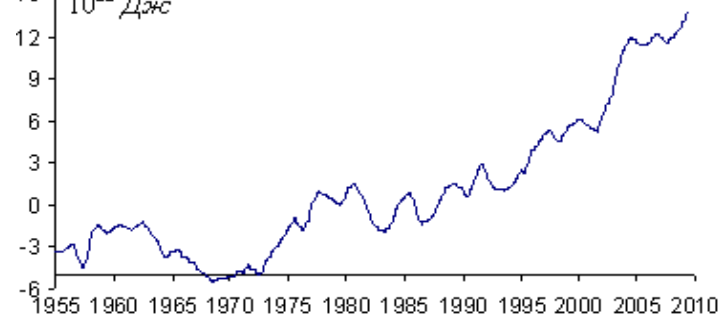

u)

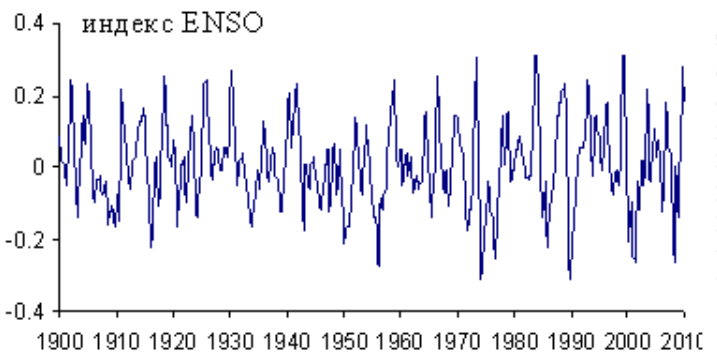

w)

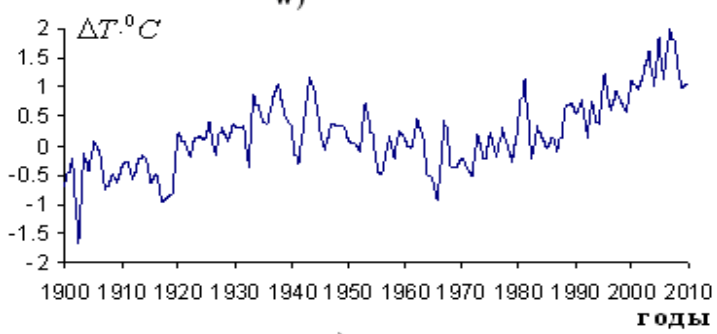

y) рактеристик $\varphi_{f}(a, b)$ переменных, характеризующих тенденции и согласованность их изменений в продолжительном интервале времени. Из графиков рис. $2, b$ следует, что изменения всех сравниваемых переменных $f_{1}, f_{5}, f_{11}, f_{16}$ в наблюдаемом интервале времени, в 1656,5-2009 гг., синхронизованы; в минимуме Муандера [10], в 1645-1715 гг. все переменные однонаправлено, ступенчатыми шагами уменьшаются; в минимуме Дальтона, в 1790-1820 гг. наблюдается скачкообразные росты $f_{1}$ и $f_{16}$ и убывания $f_{5}$ и $f_{11}$. В 1801,5 г. переменная $f_{1}$ находится в максимуме роста. В современном максимуме, в 1950-2004 гг., все переменные находятся в максимуме своих ростов. В так называемом минимуме, с 2004 г., все переменные имеют тенденцию к уменьшению. На графиках рис. 2, $b$ в 1912-1930 гг. все переменные находятся в минимумах своих значений. Этот период характеризуется началом роста приземной глобальной температуры. Графики на рис. $2, a, b$ и табл. 2 в первой части статьи показывают, что изменения переменных $f_{1}, f_{5}$, $f_{11}, f_{16}$ согласованы с изменениями переменной $f_{1}-$ барицентрическим движением Солнца.
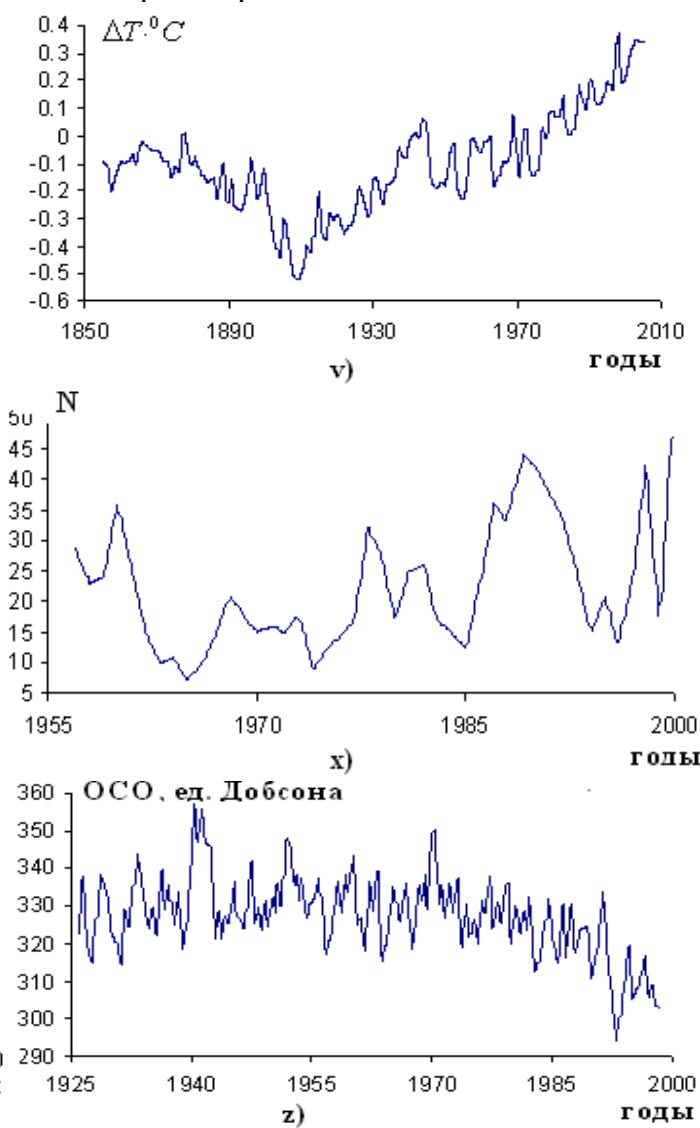

Рис. 1. Графики изменений климатических и тектонических факторов: $u) f_{2 l}(t)$ - ход изменения теплосодержания 8 слое 0-700 м Мирового океана, умноженная на $10^{22}$, в Джсулях [4]; v) $f_{22}(t)$ - ход аномалий температуры поверхности океана $\Delta T{ }^{\circ} \mathrm{C}$ в зоне от $60^{\circ} \mathrm{S}$ до $60^{\circ} \mathrm{N}$ по данным реконструкции T.M. Smith, R.W. Reynolds [57; w) $f_{23}(t)$ - вариачии индекса южного колебания/Эль-Ниньо (ENSO) в 1900-2010 г2. [6]; x) $f_{24}(t)$ - количество магнитных бурь в год в 1955-2000 г2. Г77; y) $f_{55}(t)$ - ход изменения аномалии температуры воздуха в Арктике в 1900-2010 г2. [87; z) $f_{26}(t)$ - динамика изменения озонового слоя над Арозой (Швейцария), в миллиатмосферных сантиметрах (матм. см) или в ед. Добсона [9]

Fig. 1. Graphs of changes in climatic and tectonic factors: $u$ ) the course of changes in heat content in the layer 0-700 $\mathrm{m}$ of the World Ocean, multiplied by $10^{22}$, in Joules [4]; v) the course of anomalies in the temperature of the ocean surface at $\Delta T{ }^{\circ} \mathrm{C}$ in the zone from $60^{\circ} \mathrm{S}$ to $60^{\circ} \mathrm{N}$ according to the reconstruction of T.M. Smith, R.W. Reynolds [5]; w) variations of the index of southern oscillations/El Nino in 1900-2010 [6]; x) the number of magnetic storms per year in 1955-2000 [7]; y) the course of changes in air temperature anomalies in the Arctic in 1900-2010 [8]; z) the dynamics of changes in the ozone layer over Arosa (Switzerland) in parts per billion (in units of Dobson) [9] 
Характерно то, что изменения фазо-временных характеристик переменных $\varphi_{f}(a, b)$ солнечной активности $f_{5}$ и вулканических извержений $f_{11}$ во всем интервале наблюдений на графиках рис. $2, b$ почти синхронны с небольшим сдвигом по времени и по отношению к ним изменения переменной $f_{1}$ часто происходят в противофазе, в особенности в 1792-1857 гг.

На графиках рис. 2 , с на всем интервале наблюдений в 1656,5-2009 гг. прослеживается высокая, почти синхронная согласованность относительных изменений пар $\varphi_{f_{15}}(a, b)-\varphi_{f_{16}}(a, b)$ и $\varphi_{f_{15}}(a, b)-\varphi_{f_{5}}(a, b)$ с коэффициентом корреляции $r=0,82$ При этом переменная $f_{1}$

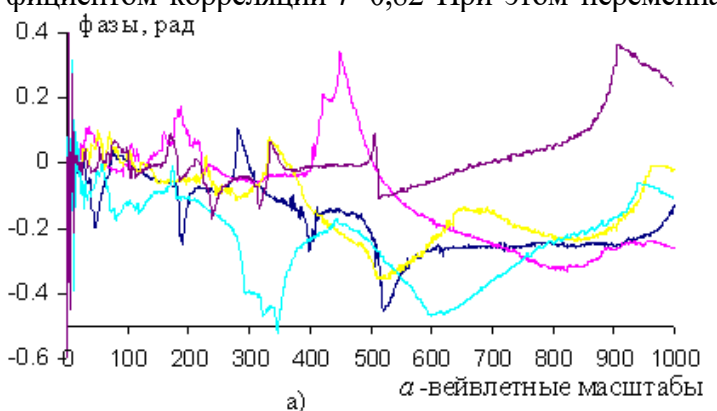

$$
\begin{array}{r}
\varphi_{f_{1}}(a, 5) \\
-\varphi_{f_{s}}(a, 5) \\
\varphi_{f_{14}}(a, 5) \\
-\varphi_{f_{16}}(a, 5) \\
-\varphi_{f_{15}}(a, 5)
\end{array}
$$

коррелирована с переменными $f_{5}$ и $f_{11} \mathrm{c}$ коэффициентами 0,55 и 0,77 , а переменная $f_{11} \mathrm{c} f_{16}$ с коэффициентом 0,40 , соответственно. Такая закономерность относительных изменений четырех функций описывается почти идентичными линейными уравнениями тенденций, приведенных на рис. 2, с, в которых рост приземной температуры $f_{15}$ в среднем опережает как рост двуокиси углерода $f_{16}$, так и рост солнечной активности $f_{5}$ с коэффициентом линейного тренда 0,0026 радиан в исследуемом интервале времени. Такая закономерность характеризует, что переменные $f_{5}$ и $f_{16}$ сильно согласованы с изменениями приземной температуры $f_{15}$.
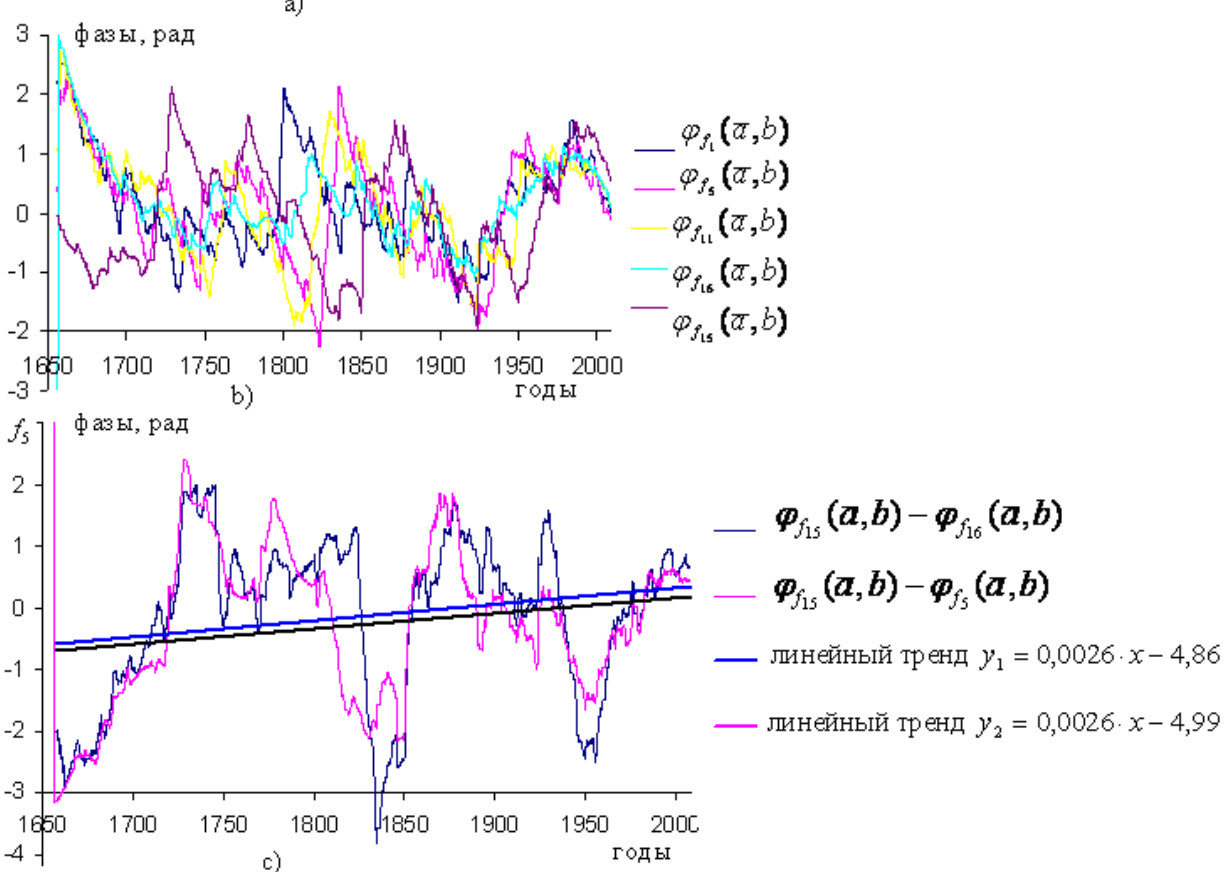

Рис. 2. Графики изменений вейвлетных характеристик в 1656,5-2009 г2.: а) вейвлетных фазо-частотных характеристик: $\varphi_{f_{1}}(a, \bar{b})$ - движения Солниа относительно барищентра, $\varphi_{f_{5}}(a, \bar{b})-$ солнечной активности, $\varphi_{f_{f_{1}}}(a, \bar{b})-$ вулканических извержений, $\varphi_{f_{15}}(a, \bar{b})$ - приземной температуры и $\varphi_{f_{16}}(a, \bar{b})-\mathrm{CO}_{2}$. Изменениям частот переменных на рисунке соответствуют изменения масштаба [1:1000] вейвлета по абсииссе; b) вейвлетных фазо-временных характеристик: $\varphi_{f_{1}}(a, b)$ - движения Солнца относительно барицентра, $\varphi_{f_{5}}(a, b)-$ солнечной активности, $\varphi_{f_{11}}(a, b)$ - вулканических извержений, $\varphi_{f_{15}}(a, b)$ - приземной температуры и $\varphi_{f_{16}}(a, b)-C O_{2}$. Характеристики получены с использованием вейвлета 'сgаи5' с масштабами [1:1000]. c) относительных изменений вейвлетных фазо-временных характеристик: $\varphi_{f_{15}}(\bar{a}, b)-\varphi_{f_{5}}(\bar{a}, b), \varphi_{f_{15}}(\bar{a}, b)-\varphi_{f_{16}}(\bar{a}, b)$ и их линейные аппроксимачии

Fig. 2. Graphs of changes in wavelet characteristics in 1656,5-2009: a) in wavelet phase-frequency characteristics: $\varphi_{f_{1}}(a, \bar{b})-$ the movement of the Sun relative to the barycenter, $\varphi_{f_{5}}(a, \bar{b})$ - solar activity, $\varphi_{f_{11}}(a, \bar{b})$-volcanic eruptions, $\varphi_{f_{15}}(a, \bar{b})-$ surface temperature and $\varphi_{f_{16}}(a, b)-\mathrm{CO}_{2}$. Changes in the frequencies of the variables in the figure correspond to changes in the wavelet scale [1:1000] on the abscissa; $b$ ) in wavelet phase-time characteristics: the movement of the Sun relative to the barycenter, solar activity, volcanic eruptions, the surface temperature and $\mathrm{CO}_{2}$. Characteristics obtained using a wavelet with scales [1:1000]; $c)$ relative changes in wavelet phase-time characteristics $\varphi_{f_{15}}(\bar{a}, b)-\varphi_{f_{5}}(\bar{a}, b), \varphi_{f_{15}}(\bar{a}, b)-\varphi_{f_{16}}(\bar{a}, b):$ and their linear approximations changes in phase-time characteristics 
Более наглядное представление об относительных изменениях главных климатообразующих факторах можно получить построением изображений временных вейвлетных фазо-частотных функций между сравниваемыми вейвлетными фазо-временными характеристиками. Такие изображения представлены на рис. 3. Они характеризуют закономерности запаздываний по фазе и времени сравниваемых функций. Эти процессы периодические, с характерными частотами. Изображение на рис. 3, a характеризует запаздывание по фазе и времени вулканических извержений $f_{11}$ относительно изменения расстояния $R$ Солнца относительно барицентра $f_{1}$. Периодичности этого процесса равны: $162,132,62,2(5,5), 33,7(5,6), 19,7(2,2)$, $12,2(3,4), 8,8(2,2), 4,7(1,2), 2,6(0,8)$ лет. В скобках указаны стандартные отклонения периодов от средних значений. В современности на уровне вейвлетнего масштаба $a=100$ рост вулканических извержений $f_{11}$ опережает рост $f_{1}$. Изображение на рис. $3, b$ характеризует закономерность опережения роста вулканических извержений $f_{11}$, рост двуокиси углерода $\mathrm{CO}_{2}$ $f_{16}$ с периодичностями $157,1,135,1,64,6(3,8), 33(7,2)$,
$18,1(4,6), 10,9(2,9), 8,7(2,3), 4,7(1,0)$ и $2,7(0,71)$ лет. Как видно из рисунка, в современности на уровне $a=1000$ рост вулканических извержений $f_{11}$ опережает рост $\mathrm{CO}_{2}$. Характерно, что разности фаз переменных $\varphi_{f_{1}}(a, b)-\varphi_{f_{11}}(a, b)$ и $\varphi_{f_{11}}(a, b)-\varphi_{f_{16}}(a, b)$ изменяются почти синхронно, но в противофазе с коэффициентом корреляции $R=-0,81$, подтверждая генетическое единство переменных $f_{1}, f_{11}$ и $f_{16}$. Изображение на рис. 3, $c$ характеризует опережение роста приземной температуры $f_{15}$, рост $f_{16}$ с периодами $133,6,122,60,3$ $(9,0), 11,4(4,2), 8,2(1,7), 4,1(1,2), 2,8(0,7)$ лет. В современности, на уровне $a=1000$, рост приземной температуры $f_{15}$ опережает рост $\mathrm{CO}_{2} f_{16}$. Периодичности сравниваемых функций близки друг другу и прогнозируемы с некоторой точностью на уровнях, задаваемых исследователем масштабах $a$ вейвлета [11]. При этом прогнозируемые кривые, как видно из рис. 4 в первой части статьи разреза функции $\varphi_{f}(a, b)$, почти периодические и легко прогнозируемы методом, описанным в [11].
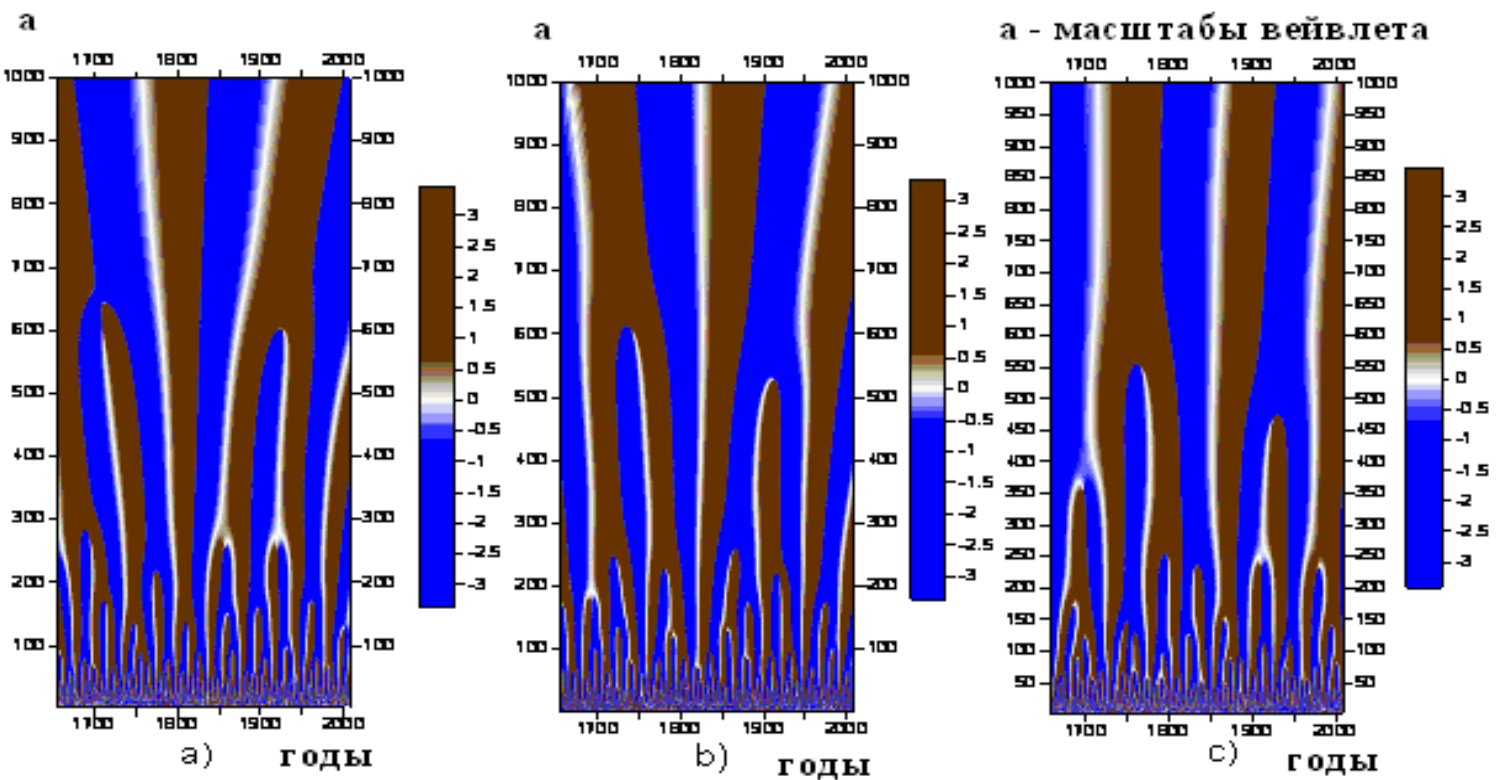

Pис. 3. Изображения временных вейвлетных фазо-частотных функций разностей вейвлетных фазо-временных характеристик: a) $\left.\varphi_{f_{1}}(a, b)-\varphi_{f_{11}}(a, b), \quad b\right) \quad \varphi_{f_{11}}(a, b)-\varphi_{f_{16}}(a, b), \quad$ c) $\varphi_{f_{15}}(a, b)-\varphi_{f_{16}}(a, b)$ в $1656,5-200922$. По ординатам изображений отмечены масштабы вейвлетов а [1:1000]

Fig. 3. Images of wavelet phase-frequency functions of the differences of wavelet phase-time characteristics: a) $\left.\left.\varphi_{f_{1}}(a, b)-\varphi_{f_{11}}(a, b), b\right) \varphi_{f_{11}}(a, b)-\varphi_{f_{16}}(a, b), c\right) \varphi_{f_{15}}(a, b)-\varphi_{f_{16}}(a, b)$ in 1656,5-2009. The scales of wavelets a[1:1000] are marked on the ordinates of the images

\section{Самоорганизующиеся колебания: Тихоокеанское} декадное, Североатлантическое, Южное/Эль-Ниньо

Вейвлетный фазо-частотный и корреляционный анализ гелиокосмических и климатических переменных показывает, что в циклическом изменении климатических переменных участвуют два главных фактора: периодические изменения, обусловленные гравитационным воздействием планет Солнечной системы и сил, образующихся при взаимодействии Солнечной энергии и энергии Космоса с атмосферой, биосферой и океаносферой Земли. Влияние этих сил на изменение климатических переменных может быть обнаружено и вычислено с использованием вейвлетных фазо-частотных $\varphi_{f}(a, b)$ и фазо-временных характеристик $\varphi_{f}(a, b)$ переменных.

Из сравнений коэффициентов корреляций между переменными в табл. 1, полученных при использовании фазо-частотных характеристик $\varphi_{f}(a, \bar{b})$, следует что: 
- ход изменения скорости вращения Земли $f_{6}$ и длительности земных суток $f_{10}$ (LOD) в сильной степени, с $k>0,73$, обусловлены асимметричными движениями Солнца $f_{1}$ и $f_{2}$;

- изменения переменных $f_{6}$ и $f_{10}$ существенно согласованы с изменениями переменных $f_{17}, f_{18}, f_{23}$;

- вариации индекса Тихоокеанского (PDO) колебания (строка $f_{18}$ ) существенно, с коэффициентами $r=0,47 \ldots 0,58$, зависят от вариаций переменных $f_{1}$, $f_{2}, f_{5}, f_{6}, f_{10}$;

- вариации индекса Североатлантического декадного колебания $f_{17}$, и в большей степени вариации индекса Южного колебания/Эль-Ниньо $f_{23}$, также индуцируются изменениями переменных $f_{1}, f_{2}, f_{5}$, $f_{6}, f_{10}$ с коэффициентами $r=0,12 \ldots 0,33$; вариации $f_{23}$ существенно зависят от изменений $f_{18}$ Тихоокеанских декадных колебаний с $k>0,58$.

В табл. 1 полученные с использованием вейвлетных фазо-временных характеристик $\varphi_{f}(a, b)$ коэффициенты в строках $f_{17}$ и $f_{23}$ сильно отличаются от коэффициентов, полученных с использованием преобразований $\varphi_{f}(a, \bar{b})$. Это отличие наблюдается и в строке $f_{18}$ в зависимости от изменений $f_{17}$.

Таблица 1. Корреляции вейвлетных фазо-частотных и фазо-временных характеристик гелиокосмических и климатических переменных по наблюдениям 1900-2000 г2.

Table 1. Correlations of wavelet phase-frequency and phase-time characteristics of helio-cosmic and climatic variables by observations in 1900-2000

\begin{tabular}{|c|c|c|c|c|c|c|c|c|c|c|c|c|c|}
\hline $\begin{array}{c}\text { Методы } \\
\text { Methods }\end{array}$ & \multicolumn{5}{|c|}{ Фазо-частотные характеристики } & \multicolumn{6}{c|}{ Фазо-временные характеристики } \\
Phase-time characteristics $\varphi_{f}(\bar{a}(1: 700), b)$
\end{tabular}

Примечание: вычисленные по критерию Стьюдента коэффициенты корреляции [12] значимы при аbc(r)>0,09 с вероятностью $p=0,95$

Note: the correlation coefficients abc(r)>0,09 calculated by the Student criterion [12] are significant with probability p=0,95.

Причиной таких отличий является то, что изменчивости переменных $f_{17}, f_{18}$ и $f_{23}$ по табл. 1 в большей степени обусловлены вариациями наземных и океанических температурных переменных $f_{15}, f_{19} . . f_{23}$, чем вариациями других переменных. Это означает, что в формировании Североатлантического $f_{17}$, Тихоокеанского декадного $f_{18}$ и Южного /Эль-Ниньо колебания $f_{23}$, кроме Солнечно-космических переменных, участвуют и синергетические факторы взаимодействия океана, атмосферы и биосферы Земли в наблюдаемом интервале времени в парах $\left(f_{6}, f_{17}\right),\left(f_{10}, f_{17}\right),\left(f_{10}, f_{18}\right),\left(f_{10}, f_{23}\right)$,. Эти колебательные процессы сопровождаются приложением на поверхность Земли импульсов сил, изменяющих скорость ее вращения $f_{6}$ и длительность земных суток $f_{10}$. На изменения переменной $f_{10}$ влияют также Лунносолнечные приливные колебания [13-15]. Источники, влияющие на эти изменения, отображаются на графиках плотностей распределений фазо-временных характеристик функций $\varphi_{f_{6}}(a, b)$ и $\varphi_{f_{10}}(\bar{a}, b)$ (рис. 4$)$.

Как видно из рис. 4, в изменении переменных принимают участие три источника, два из которых сильно выражены. Этими источниками могут быть силы гравитационного поля асимметричных движений Солнца (факторы $f_{1}, f_{2}$ в табл. 2 в первой части статьи и в табл. 1) и факторы $f_{17}, f_{18}, f_{23}$ в табл. 1 . Они оказывают на движение Земли механические воздействия в виде изменений атмосферных давлений, движений воздушных масс и океанических течений. Характерно то, что обе функции почти идентичны и антисимметричны по фазе.
Табл. 1 является характеристикой тесноты связи между изменениями гелиокосмических переменных $f_{1}, f_{2}$, изменениями параметров движения Земли $f_{6}, f_{10}$ и наземными колебательными процессами $f_{17}, f_{18}, f_{23}$ - характеристикой связей трех взаимосвязанных осцилляторов. В этой системе параметры движения Земли $f_{6} f_{10}$ обусловлены изменениями переменных $f_{1}, f_{2}$ и переменных $f_{17}, f_{18}, f_{23}$. Эти связи характеризуются табл. 1 и табл. 2 в первой части статьи. В результате взаимодействия этих переменных (колебательных контуров) формируется еще более сложная самоорганизующаяся колебательная система, работа которой поддерживается энергией Солнца.

Графики согласованных изменений групп осцилляторов $f_{17}, f_{18}, f_{23}$ и $f_{1}, f_{5}, f_{11}$ в фазо-частотной и фазовременной областях их изменений в 1900-2000 гг. приведены на рис. 5.

На рис. 5 наблюдается высокая согласованность изменений переменных с $r=0,70 \ldots 0,86$ при сильной нестационарности изменений функций, и этот процесс поддерживается барицентрическим движением Солнца $f_{1}$, Солнечной активностью $f_{5}$ и вулканическими извержениями $f_{11}$. На графиках рис. 5 изменения переменных четко разделены на два класса как в фазо-частотной (рис. $5, a$ ), так в фазо-временной (рис. $5, b$ ) областях. К одному классу относятся изменения переменных $f_{1}, f_{5}, f_{11}$, а к второму $-f_{17}, f_{18}, f_{23}$; причем изменения переменных $f_{17}, f_{18}, f_{23}$ подчиняются изменениям $f_{1}, f_{5}, f_{11}$, что четко прослеживается во всем интервале наблюдений, и в особенности, в противофазном изменении двух групп переменных в 1970-1977 гг. (рис. 5, b). 

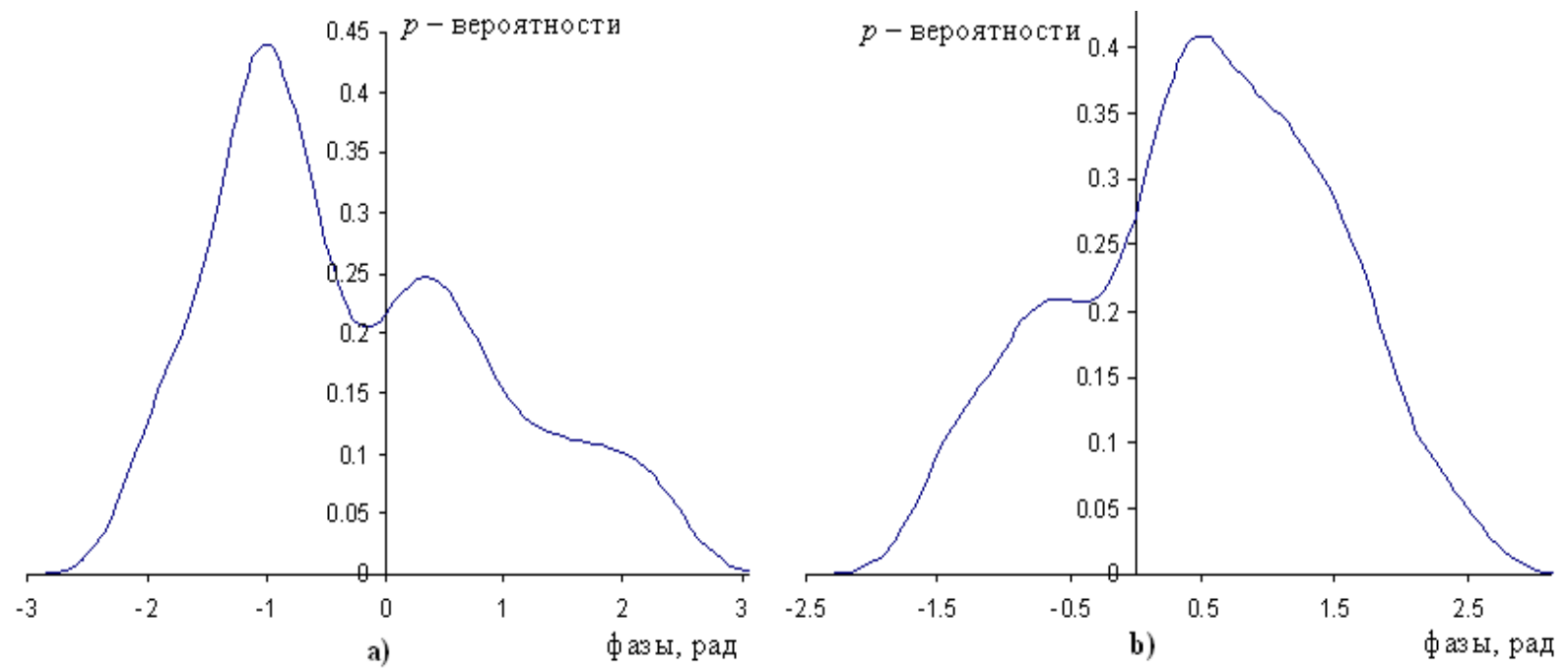

Рис. 4. Графики плотностей распределений вейвлетных фазо-временных характеристик: а) $\varphi_{f_{6}}(a, b)$ скорости вращения Земли; b) изменений длительности суток $\varphi_{f_{10}}(a, b)$, по наблюдениям в 1900-2000 г2. Фазы переменных изменяются в интервале Ғ $\pi$ по абсииссе

Fig. 4. Graphs of density distributions of wavelet phase-time characteristics: a) $\varphi_{f_{6}}(a, b)$ the speed of rotation of the Earth; b) changes in the length of the day $\varphi_{f_{10}}(a, b)$ by observations in 1900-2000. The phases of the variables vary in the interval $\mp \pi$ on the abscissa
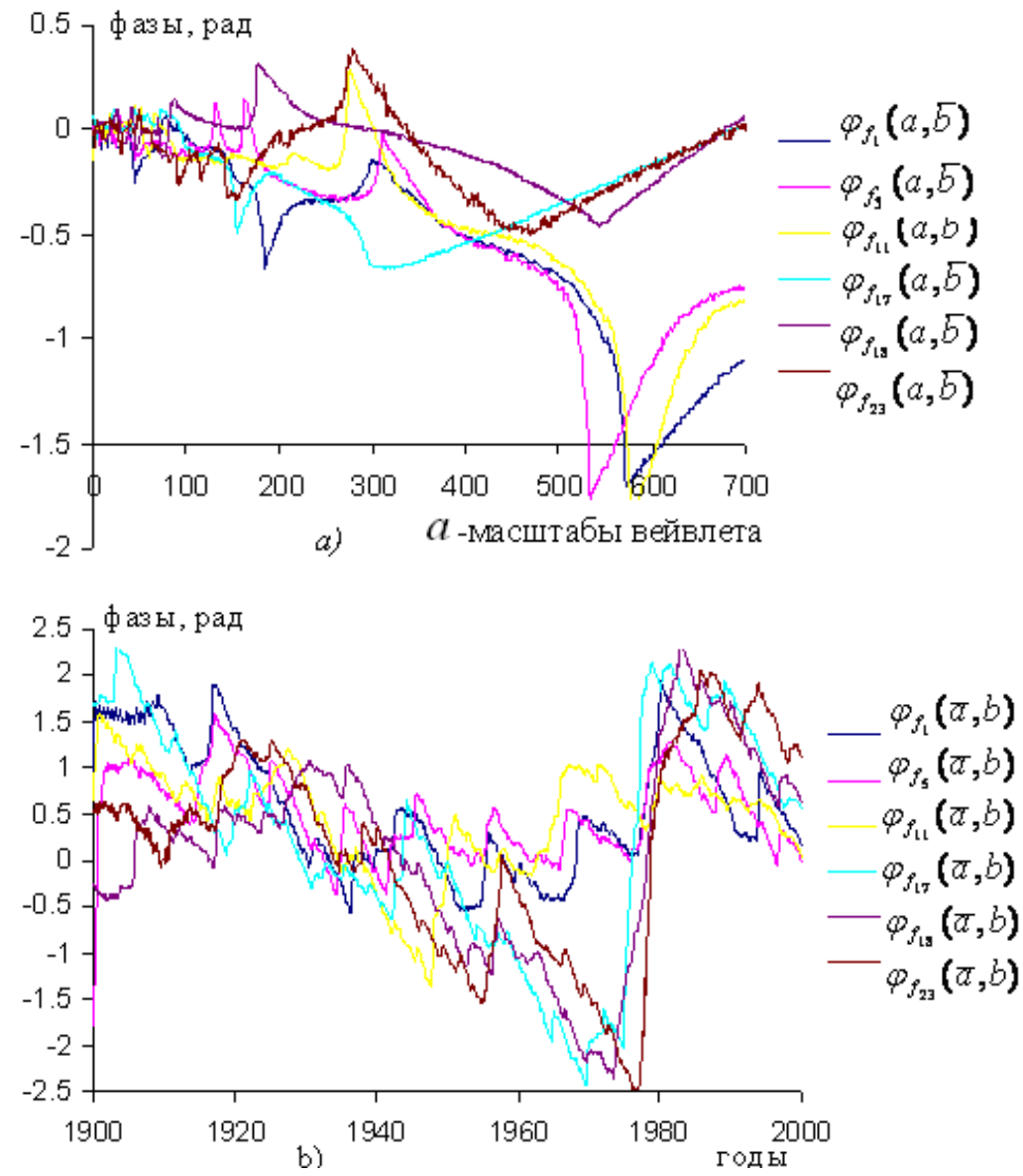

Pис. 5. Графики согласованности изменений вейвлетных: а) фазо-частотных характеристик в масштабах а [1:700] по абсииссе; b) фазо-временных характеристик в 1900-2000 гг. переменных (Североатлантического $f_{17}$, Tuхоокеанского декадного (PDO) $f_{18}$, Южного /Ель-Ниньо $f_{23}$ и $f_{1}, f_{5}, f_{11}$ колебаний)

Fig. 5. Graphs of consistency of changes in wavelet: a) phase-frequency characteristics on a abscissa scale a(1:700); b) phase-time characteristics in 1900-2000 of variables (North Atlantic $f_{17}$, Pacific Decade (PDO) $f_{18}$, South/El Nino $f_{23}$ and $f_{1}, f_{5}, f_{11}$ oscillations) 


\section{Анализ согласованности изменений расстояния $R$ Солнца до барицентра, вулканических извержений Земли, озонового слоя в стратосфере и температуры воздуха в Арктической зоне России}

Исследования проводятся с использованием графиков, приведенных на рис. 1. Плотность распределения вероятностей изменения температуры воздуха в Арктической зоне по наблюдениям в 1900-2010 гг. описывается графиком на рис. $6, a$. Из графика следует, что температура воздуха в Арктике формируется под влиянием разнозначных почти симметричных по фазе факторов: солнечной энергии при изменениях озонового слоя атмосферы Земли над Арктикой и воздушных потоков, формируемых на поверхности Земли и океанов с разными ритмичностями. В формировании самого озонового слоя над Арозой по

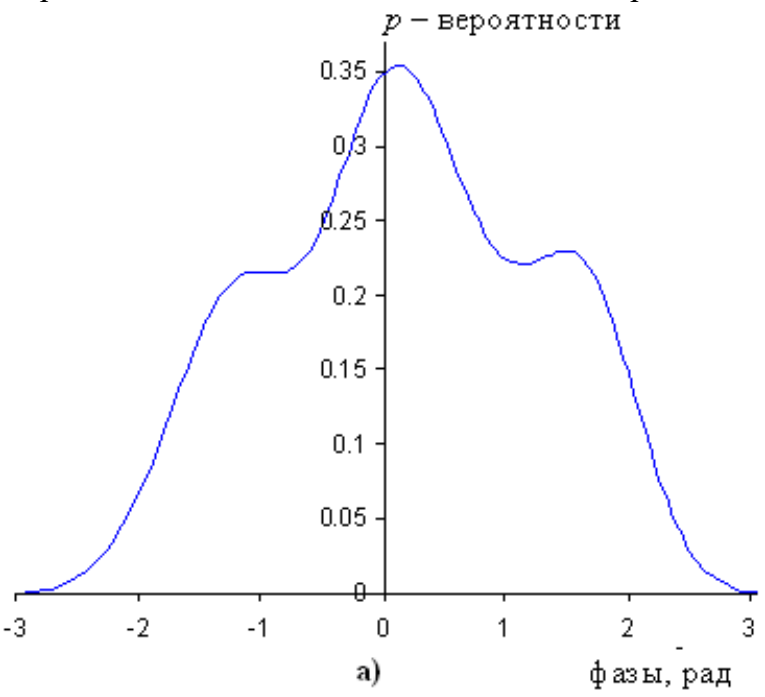

рис. $6, b$ выявляются также три фактора. Это может быть солнечная радиация, озоноразрушающие составляющие вулканических извержений Земли и производственной деятельности человечества, геологогеографическая позиция Западной Европы [16-20]. Раздел, содержащий о механизмах изменчивости и влиянии озонового слоя в средней атмосфере на климат Земли, содержится в [21].

В табл. 3 приводятся коэффициенты корреляций между вейвлетными фазо-частотными характеристикми $\varphi_{f}(a, \bar{b})$ сравниваемых переменных. Они характеризуют меры согласованности изменений переменных по фазо-частотному составу функций $\varphi_{f_{i}}(a(1: 500), \bar{b}), i=1,5,11,15,16,25,26 \quad$ в наблюдаемом интервале времени в 1926-1998.

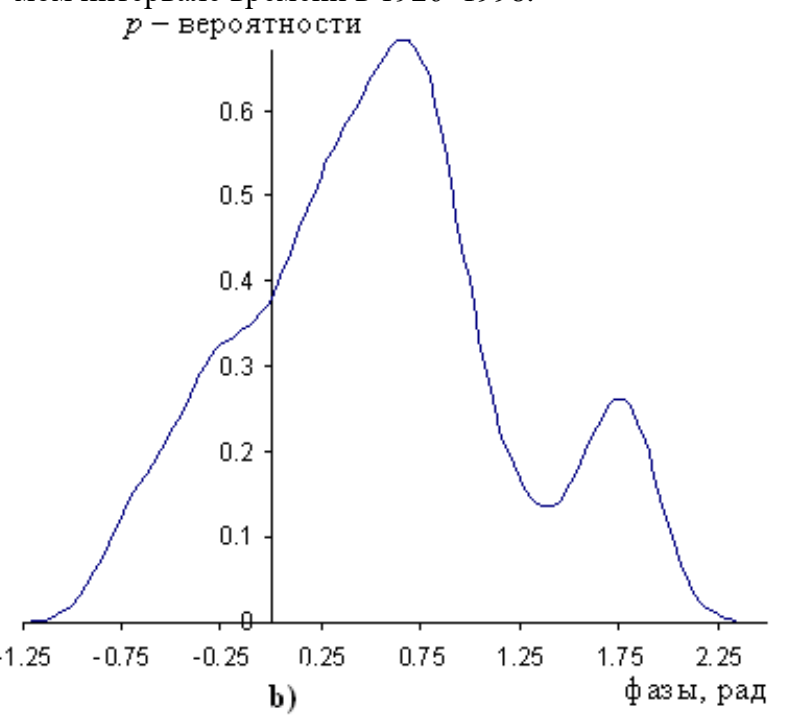

Рис. 6. Графики плотностей распределений фазо-временных характеристик $\varphi(a, b)$ : a) температуры воздуха в Арктике $\left.f_{25}(t) ; b\right)$ озонового слоя над Арозой $f_{26}(t)$ в 1926-1998 г2. Фазы переменных изменяются в интервале $\mp \pi$ nо абсииссе

Fig. 6. Density plots of phase-time characteristics $\varphi(a, b): a)$ air temperature in the Arctic $f_{25}(t)$; $\left.b\right)$ the ozone layer above Arosa $f_{26}(t)$ in 1926-1998. The phases of the variables vary in the interval $\mp \pi$ on the abscissa

Таблица 2. Коэффициенты корреляций $r$ изменений расстояния $R$ Солнца относительно барицентра $f_{1}$, вулканических извержений Земли $f_{11}$, озонового слоя в стратосфере над Арозой в Швейцарии $f_{26}$, температуры воздуха в Арктической зоне $f_{25}$ и других климатических переменных по наблюдениям в 1926-1998,2 г2., вычисленных по вейвлетным фазо-частотным и фазо-временным характеристикам функиий $\varphi_{f}(a(1: 500), b)$

Table 2. Correlation coefficients $r$ of changes in the distance $R$ of the Sun to the barycenter $f_{1}$, volcanic eruptions of the Earth $f_{11}$, the ozone layer in the stratosphere over Arosa in Switzerland $f_{26}$, air temperature in the Arctic zone $f_{25}$ and other climatic variables according to observations in 1926-1998,2 by wavelet phase-frequency and phasetime characteristics of functions $\varphi_{f}(a(1: 500), b)$

\begin{tabular}{|c|c|c|c|c|c|c|c|c|c|c|c|c|c|c|}
\hline $\begin{array}{l}\text { Методы } \\
\text { Methods }\end{array}$ & & $\begin{array}{r}\Phi \\
\text { Phas }\end{array}$ & $\begin{array}{l}\text { o-част } \\
\text { requen }\end{array}$ & $\begin{array}{l}\text { ные ха] } \\
\text { charact }\end{array}$ & $\begin{array}{l}\text { терис } \\
\text { stics }\end{array}$ & $a, \bar{b})$ & & & & $\begin{array}{l}\text { o-spe } \\
\text { e-time }\end{array}$ & $\begin{array}{l}\text { iные } \\
\text { aracte }\end{array}$ & $\begin{array}{l}\text { актерь } \\
\text { ics } \varphi\end{array}$ & $\begin{array}{l}\text { ики } \\
, b)\end{array}$ & \\
\hline $\begin{array}{c}\text { Факторы } \\
\text { Factors }\end{array}$ & $f_{1}$ & $f_{5}$ & $f_{11}$ & $f_{15}$ & $f_{16}$ & $f_{25}$ & $f_{26}$ & $f_{1}$ & $f_{5}$ & $f_{11}$ & $f_{15}$ & $f_{16}$ & $f_{25}$ & $f_{26}$ \\
\hline$f_{1}$ & 1 & & & & & & & 1 & & & & & & \\
\hline$f_{5}$ & 0,96 & 1 & & & & & & 0,81 & 1 & & & & & \\
\hline$f_{11}$ & 0,93 & 0,93 & 1 & & & & & 0,30 & 0,58 & 1 & & & & \\
\hline$f_{15}$ & $-0,24$ & $-0,24$ & $-0,26$ & 1 & & & & 0,53 & 0,48 & 0,41 & 1 & & & \\
\hline$f_{16}$ & 0,90 & 0,81 & 0,87 & $-0,30$ & 1 & & & 0,41 & 0,69 & 0,81 & 0,39 & 1 & & \\
\hline$f_{25}$ & 0,46 & 0,51 & 0,49 & 0,45 & 0,30 & 1 & & 0,61 & 0,70 & 0,55 & 0,58 & 0,62 & 1 & \\
\hline$f_{26}$ & 0,94 & 0,90 & 0,94 & $-0,27$ & 0,95 & 0,44 & 1 & 0,40 & 0,66 & 0,80 & 0,36 & 0,97 & 0,58 & 1 \\
\hline
\end{tabular}

Примечание. Коэффичиенты коррелячий с $r>0,065$ значимы с вероятностью 0,95 по критерию Стьюдента.

Note. The correlation coefficients with $r>0,065$ are significant with a probability of 0,95 according to the Student criterion. 
Как видно из табл. 2, при сопоставлении фазочастотных характеристик $\varphi_{f}(a, \bar{b})$ сравниваемых сигналов наблюдается значительная согласованность изменений переменных $f_{26}-$ озонового слоя, и $f_{25}-$ температуры воздуха в Арктике, с изменениями $f_{1}, f_{5}$ и $f_{11}$ (расстояния $R$ Солнца до барицентра, Солнечной активности и вулканических извержений) с коэффициентами корреляций $r \geq 0,46$. Уменьшение размеров озонового слоя $f_{26}$ сопровождается ростом температуры воздуха в Арктике $f_{25}$ с коэффициентом $r=0,44$. Значительно согласованы рост концентрации $\mathrm{CO}_{2}$ в атмосфере $f_{16}$ и изменения (уменьшение) озонового слоя $f_{26} \mathrm{c} r=0,95$ с вулканическими извержениями $f_{11} \mathrm{c}$ $r=0,87$; наблюдается отрицательная согласованность изменений приземной температуры $f_{15} \mathrm{c}$ изменениями $f_{1}, f_{5}, f_{11}, f_{16}$ и $f_{26}$ с коэффициентами $r \approx-0,25$. Заметим, что все исследуемые переменные изменяются циклически, и коэффициенты корреляций между переменными в некоторых интервалах могут быть и отрицательными, при этом сравниваемые сигналы будут находиться на некоторых частотах в противофазе.

Графики изменений вейвлетных фазо-частотных характеристик $\varphi_{f}(a, \bar{b})$ переменных, приведенных в табл. 2, в масштабах $a(1: 500)$ представлены на рис. 7. На рисунке графики изменений переменных четко раз- делились на два класса, характеризующих их происхождение. К одному классу относятся изменения переменных $f_{1}, f_{5}, f_{11}, f_{16}, f_{26}$, обусловленные изменениями $f_{1}$, расстояния $R$ Солнца относительно барицентра; к другому классу относятся изменения приземной температуры $f_{15}$ и температуры в Арктике $f_{25}$, обусловленные перераспределением солнечной энергии, получаемой Землей, движениями атмосферных воздушных и океанических водных потоков энергии. Принадлежность изменений переменных к двум типам факторов влияния в табл. 2 выражается в изменении (росте) коэффициентов корреляций между фазо-временными характеристиками $\varphi_{f}(a, b)$ в строках $f_{15}$ и $f_{25}$ во второй половине табл. 2.

Заметим, что изменения вейвлетных фазовременные характеристик $\varphi_{f}(\bar{a}, b)$ этих же переменных в том же интервале времени также происходят в двух классах, в классе с переменными $f_{1}, f_{5}, f_{11}, f_{16}, f_{26}$ и в класс с переменными $f_{15}, f_{25}$. Эти результаты доказывают, что основным источником двуокиси углерода $\mathrm{CO}_{2}$ в атмосфере Земли и озоноразрушающих источников в стратосфере является вулканическая деятельность Земли, управляемая движением Солнца относительно барицентра, обусловленным движениями планет Солнечной системы.

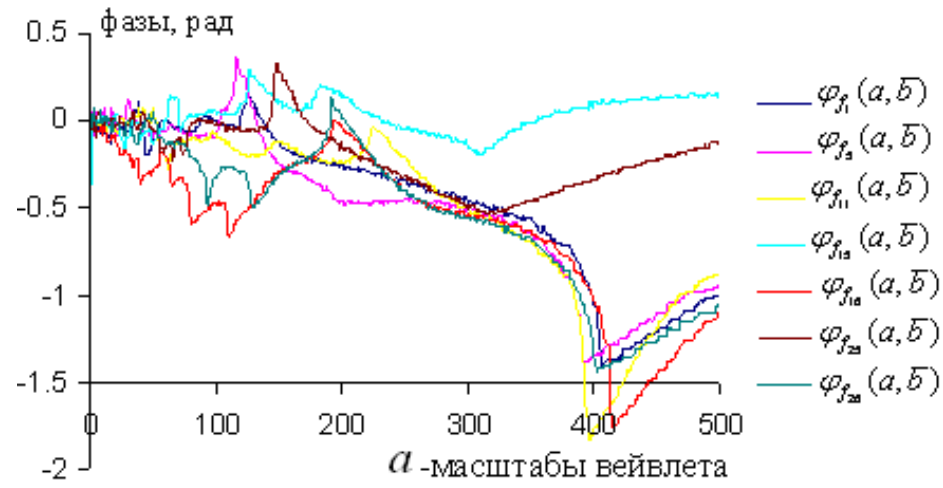

Рис. 7. Графики изменений двух классов вейвлетных фазо-частотных характеристик $\varphi_{f}(a, \bar{b})$ переменных в Арктической зоне в 1926-1998,2 г2. в вейвлетных масштабах а[1:500] по абсииссе. К первому классу относятся изменения переменных: $\varphi_{1}(a, \bar{b})$ - бароцентрического движения Солнияа, $\varphi_{5}(a, \bar{b})$ - солнечной активности, $\varphi_{11}(a, \bar{b})$ - вулканических извержений, $\varphi_{16}(a, \bar{b})$ - концентрации двуокиси углерода в атмосфере и $\varphi_{26}(a, \bar{b})-$ озонового слоя; ко второму классу относятся изменения переменных: $\varphi_{15}(a, \bar{b})-$ приземной температуры $и$ $\varphi_{25}(a, \bar{b})$ - температуры в арктической зоне

Fig. 7. Graphs of changes in two classes of wavelet phase-frequency characteristics $\varphi_{f}(a, \bar{b})$ of variables in the Arctic zone in 1926-1998,2 in wavelet scales a 1:500] along the abscissa. The first class includes changes in variables: $\varphi_{1}(a, \bar{b})$ the barocentric movement of the Sun, $\varphi_{5}(a, \bar{b})$ solar activity, $\varphi_{11}(a, \bar{b})$ volcanic eruptions, $\varphi_{16}(a, \bar{b})$ the concentration of carbon dioxide in the atmosphere and the ozone layer $\varphi_{26}(a, b)$; the second class includes changes in variables: $\varphi_{15}(a, \bar{b})$ surface temperature and temperature in the Arctic zone $\varphi_{25}(a, \bar{b})$

Согласованность изменений гелиокосмических, солнечных переменных и тектонических процессов на Земле

В табл. 3 приведены коэффициенты согласованности изменений гелиокосмических переменных $f_{1}$ и $f_{2}$, солнечной активности $f_{5}$, индекса «а» геомагнитной активности Земли $f_{8}$, характеризующей взаимодей- ствие солнечного ветра и магнитосферы Земли, вулканических извержений $f_{11}$, зарегистрированных цунами $f_{12}$, землетрясений $f_{13}$ и природных катастроф $f_{14}$ в Мире в 1901-2000 гг. При этом коррелируются не сами переменные, а их вейвлетные фазо-частотные $\varphi_{f}(\bar{a}, b)$ и фазо-временные $\varphi_{f}(a, \bar{b})$ характеристики. 
Таблица 3. Корреляции вейлетных фазо-частотных и фазо-временных характеристик гелиокосмических, солнечных, климатических и тектонических переменных Земли в 1901-2000 г2.

Table 3. Correlations of the wavelet phase-frequency and phase-time characteristics of the heliocosmic, solar, climatic and tectonic variables of the Earth in 1901-2000

\begin{tabular}{|c|c|c|c|c|c|c|c|c|c|c|c|c|c|c|c|c|c|c|}
\hline \multirow{2}{*}{\begin{tabular}{|c|} 
Методы \\
Methods \\
Факторы \\
Factors \\
\end{tabular}} & \multicolumn{9}{|c|}{$\begin{array}{c}\text { Фазо-частотные характеристики } \\
\text { Phase-frequency haracteristics } \varphi_{f}(a(1: 1000), \bar{b})\end{array}$} & \multicolumn{9}{|c|}{$\begin{array}{c}\text { Фазо-временные характеристики } \\
\text { Phase-time characteristics } \varphi_{f}(\bar{a}(1: 1000), b)\end{array}$} \\
\hline & $f_{1}$ & $f_{5}$ & $f_{6}$ & $f_{8}$ & $f_{10}$ & $f_{11}$ & $f_{12}$ & $f_{13}$ & $f_{14}$ & $f_{1}$ & $f_{5}$ & $f_{6}$ & $f_{8}$ & $f_{10}$ & $f_{11}$ & $f_{12}$ & $f_{13}$ & $f_{14}$ \\
\hline$f_{1}$ & 1 & & & & & & & & & 1 & & & & & & & & \\
\hline$f_{5}$ & 0,89 & 1 & & & & & & & & 0,57 & 1 & & & & & & & \\
\hline$f_{6}$ & $-0,62$ & $-0,63$ & 1 & & & & & & & $-0,20$ & 0,25 & 1 & & & & & & \\
\hline$f_{8}$ & 0,79 & 0,95 & $-0,70$ & 1 & & & & & & 0,10 & 0,69 & 0,51 & 1 & & & & & \\
\hline$f_{10}$ & 0,92 & 0,78 & $-0,75$ & 0,73 & 1 & & & & & 0,65 & 0,15 & $-0,32$ & $-0,10$ & 1 & & & & \\
\hline$f_{11}$ & 0,96 & 0,89 & $-0,63$ & 0,80 & 0,88 & 1 & & & & 0,34 & 0,70 & 0,28 & 0,51 & 0,05 & 1 & & & \\
\hline$f_{12}$ & 0,53 & 0,44 & $-0,80$ & 0,49 & 0,66 & 0,47 & 1 & & & 0,54 & 0,04 & 0,48 & 0,45 & $-0,71$ & $-0,21$ & 1 & & \\
\hline$f_{13}$ & 0,90 & 0,88 & $-0,84$ & 0,88 & 0,94 & 0,88 & 0,68 & 1 & & 0,62 & 0,20 & $-0,16$ & 0,00 & 0,86 & 0,01 & $-0,50$ & 1 & \\
\hline$f_{14}$ & $-0,63$ & $-0,55$ & 0,40 & $-0,43$ & $-0,67$ & $-0,64$ & $-0,38$ & $-0,55$ & 1 & $-0,42$ & $-0,48$ & $-0,63$ & $-0,35$ & $-0,29$ & $-0,45$ & 0,20 & $-0,39$ & 1 \\
\hline
\end{tabular}

Примечание. Коэффициченты корреляций при $r>0,07$ на уровне значимости $\alpha=0,05$ и числе степеней свободы $k=998$ значимо отличаются от нуля с вероятностью $p=0,95$.

Note. The correlation coefficients $r>0,07$ at the significance level $\alpha=0,05$ and the number $k=998$ of degrees of freedom significantly differ from zero with a probability $p=0,95$.

Таблица отображает высокое взаимосогласованное изменение исследуемых переменных, обусловленное близостью их фазо-частотных и фазо-временных характеристик, в особенности значительны коэффициенты корреляций при использовании функций $\varphi_{f}(a, \bar{b})$ они отражают меру генетического единства сравниваемых сигналов. Это означает, что сравниваемые сигналы сильно согласованы с изменениями $f_{1}$ - изменениями движения Солнца относительно барицентра. Тектонические процессы на Земле проявляются высокими коэффициентами корреляций изменений Солнечной активности $f_{5}$, скорости вращения Земли $f_{6}$, геомагнитной активности $f_{8}$, длительности земных суток $f_{10}$, вулканических извержений $f_{11}$, активизации цунами в мире $f_{12}$, землетрясений $f_{13}$ и ростом катастрофических событий $f_{14}$. Как видно из второй половины табл. 3, использовании метода вычисления $a 2=\varphi_{f}(a, b)$, к катастрофическим событиям чув- ствительны изменения скорости вращения Земли $f_{6}$, связанные с приложением импульсов сил на поверхность Земли при катастрофических событиях. Согласованности изменений исследуемых переменных в преобразованиях $\varphi_{f}(a, b)$ отражены на графиках рис. 8 . На рисунке график изменения переменной $f_{6}$ - скорости вращения Земли, находится в противофазе с изменениями других переменных, вызванными ответной реакцией неоднородной Земли на внешние воздействия [21]. Аналогичные закономерности получены при анализе переменных в 1968-2009 гг., при этом выявлена высокая согласованность изменений напряженности общего магнитного поля Солнца $f_{9}$ с тектоническими процессами на Земле с коэффициентами $r=0,74 \ldots 0,80$ и индексом LOD c $r=0,65$; изменения переменной $f_{9}$ происходят в противофазе с изменениями других переменных.

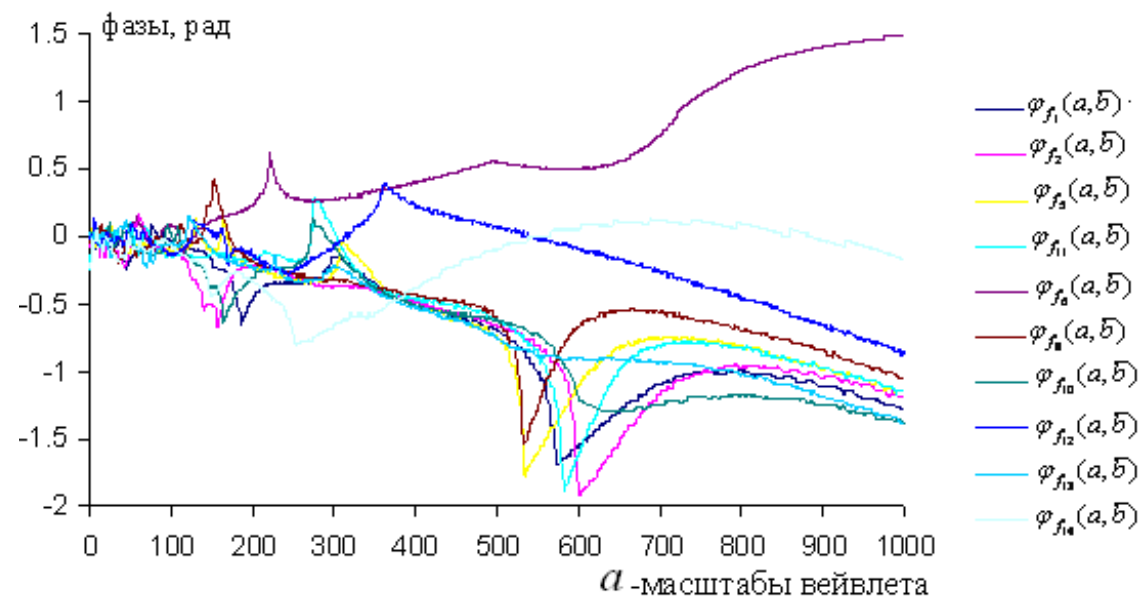

Pис. 8. Графики изменений вейвлетных фазо-частотных характеристик $\varphi_{f}(a, \bar{b})$ : гелиокосмической $f_{1}$, солнечной $f_{5}$, солнечно-земных $f_{6}, f_{8}, f_{10}$, тектонических переменных $f_{11}, f_{12}, f_{13}, f_{14}$ в 1901-2000 г2.; фазы сигналов изменяются по ординате в интервале $\mp \pi$

Fig. 8. Graphs of changes in wavelet phase-frequency characteristics $\varphi_{f}(a, \bar{b})$ : helio-space $f_{1}$, solar variables $f_{5}$, solarterrestria $f_{6}, f_{8}, f_{10}$; tectonic $f_{11}, f_{12}, f_{13}, f_{14}$ variables in 1901-2000; signal phases change ordinate in the interval $\mp \pi$ 
Основной движущей силой в этих процессах являются гравитационные силы и силы магнитного поля Солнца, обусловленные движениями планет Солнечной системы и приводящие к асимметричным движениям Солнца с изменениями сил гравитации и процессов, происходящих в неоднородной структуре Солнца. Эти силы обуславливают сложные тектонические движения с разными амплитудами в литосфере и в более глубоких неоднородных слоях Земного шара, движения ядра Земли и в неоднородной структуре Солнца [22], вращающихся вокруг своих осей. Гравитационные силы планет Солнечной системы и вращательные движения Солнца и Земли, действующие в разных направлениях, приводят к сложным тектоническим движениям в недрах Солнца и Земли.

Эти движения наблюдаются в виде эруптивных процессов на Солнце [23] и Солнечной активности, вулканических извержений, землетрясений и цунами на Земле. Движения в разных слоях Солнца приводят к изменениям напряженности общего магнитного поля Солнца $f_{9}$ [24]. В работах [25-31] анализируются процессы, происходящие в недрах Земли, в литосфере, в земной коре, гидросфере и атмосфере, без привязки этих процессов к бароцентрическим движениям Солнца - основного фактора, влияющего на динамику этих процессов.

Главным выводом исследований по этому разделу является то, что тектонические процессы, происходящие в недрах неоднородных по структуре Солнца и Земли, обусловлены асимметричными движениями Солнца $f_{1}$ относительно ее барицентра. В свою очередь такие движения Солнца обусловлены движениями планет-гигантов с разными массами вокруг Солнца на разных орбитах.

\section{Выводы}

1. Построением совместных графиков вейвлетных фазо-частотных $\varphi_{f}(a, \bar{b})$ и фазо-временных $\varphi_{f}(a, b)$

характеристик переменных $f_{1}, f_{5}, f_{11}, f_{16}$ и анализом коэффициентов корреляций между этими переменными установлена принадлежность изменений этих переменных в 1656,5-2009 гг. к одному классу; установлено, что изменения переменных $f_{5}, f_{11}$, $f_{16}$ (солнечной активности, вулканических извержений и концентрации двуокиси углерода в атмосфере) обусловлены изменениями барицентрическими движениями Солнца. $f_{1}$.

2. В 1656,5-2009 гг. синхронизованы изменения разностей фаз $\varphi_{f_{15}}(a, b)-\varphi_{f_{16}}(a, b)$ и $\varphi_{f_{15}}(a, b)-\varphi_{f_{5}}(a, b)$ с уравнениями трендов $y_{1}(t)=0,0026 t-4,86$ и $y_{2}(t)=0,0026 t-4,99$, т. е. изменения фаз $\mathrm{CO}_{2}$ и солнечной активности Sact согласованы с изменениями фазы глобальной приземной температуры.

\section{СПИСОК ЛИТЕРАТУРЫ}

1. Современные глобальные изменения природной среды. В 2-х т. Т. 1 / под ред. Клиге Р.К., Лукьяновой С.А. - М.: Научный мир, 2006. -696 с
3. Построенные изображения разностей фазовременных характеристик $\varphi_{f_{1}}(\bar{a}, b)-\varphi_{f_{11}}(\bar{a}, b)$, $\varphi_{f_{11}}(a, b)-\varphi_{f_{16}}(a, b)$ и $\varphi_{f_{15}}(a, b)-\varphi_{f_{16}}(a, b)$ позволяют установить и визуализировать закономерности изменений этих функций на задаваемых исследователем частотах, в том числе и на некоторый временной горизонт в будущем.

4. Самоорганизованные колебания: Североатлантическое $f_{17}$, Тихоокеанское декадное PDO $f_{18}$ и Южное /Эль-Ниньо $f_{23}$, принадлежащие к наземному классу, синхронизированы с изменениями переменных $f_{1}, f_{5}, f_{11}$, принадлежащих к другому, к классу изменений космического происхождения; энергетической основой этих колебаний является инсоляция Солнца.

5. Исследованиями гелиокосмических и климатических переменных, включая изменения озонового слоя $f_{26}$ над Арозой в Швейцарии, изменений температуры воздуха в Арктике $f_{25}$ в 1926-1998 гг. установлено, что изменения переменных $f_{1}, f_{5}, f_{11}$, $f_{16}, f_{26}$ относятся к классу с космическим происхождением, а изменения переменных $f_{15}, f_{25}-$ к классу с наземным происхождением.

6. Установлено, что изменения переменных $f_{5}, f_{6}$, $f_{8} \ldots f_{14}$, функционально связанные с тектоническими процессами на Земле, вместе с асимметричными движениями Солнца $f_{1}, f_{2}$ принадлежат к одному классу космического происхождения, обусловленного движением планет Солнечной системы.

7. Вейвлетная функция $\varphi_{f}(a, b)$ и ее характеристики $\varphi_{f}(a, \bar{b}), \varphi_{f}(\bar{a}, b)$

весьма информативны - с их помощью выявлены описанные выше закономерности, происходящие в климатических изменениях, они удобны для наглядного графического представления, сравнения исследуемых функций и могут быть использованы для анализа результатов исследований объектов произвольной природы.

8. Анализом многочисленных переменных, временных рядов $f_{1} \ldots f_{24}$, изменяющихся в разных интервалах времени, характеризующих относительные изменения расстояний между Солнцем и Землей, взаимодействий процессов, происходящих в недрах Солнца и Земли, вариаций движений Земли и температурных изменений в разных сферах; методом, разработанным в статье, установлена главная закономерность климатических изменений на Земле - согласованность изменений солнечной активности, вулканических извержений, концентраций двуокиси углерода, озонового слоя в атмосфере, тектонических процессов и температурных изменений на Земле под влиянием асимметричных барицентрических движений Солнца, обусловленных движением планет Солнечной системы.

2. Современные глобальные изменения природной среды. В 2-х т. Т. 2 / под ред. Клиге Р.К., Лукьяновой С.А. - М.: Научный мир, 2006. $-776 \mathrm{c}$.

3. Современные глобальные изменения природной среды. Т. 3. Факторы глобальных изменений / под ред. Клиге Р.К., Хлыстова А.И. - М.: Научный мир, 2012. - 444 с. 
4. Касимов Н.С., Клиге Р.К. Введение. Проблемы глобальных изменений // Современные глобальные изменения природной среды. Т. 3. Факторы глобальных изменений. - М.: Научный мир, 2012. - C. 11-40.

5. Smith T.M., Reynolds R.W. Extended reconstruction of global sea surface temperatures based on COADS database NOAA// Journal Climate. - 2003. - V. 16. - P. 1495-1510.

6. Гущина Д.Ю. Аномалии климата в тропиках Тихого, Индийского и Атлантического океанов // Современные глобальные изменения природной среды. Т. 1. - М.: Научный мир, 2006. C. $129-174$.

7. Obridko V.N., Golyshev S.A., Levitin A.E. Secular and cycle variations of the IMF $\mathrm{Bz}$ component and some associated geophysical effects // SOLSPA 2001 Euroconference: Solar Cycle and Space Weather. - Vico Equense, Italy, 24-29 September 2001. - P. 404-407.

8. State of Arctic. Report / J. Richter-Menge, J. Overland, A. Proshutinsky, V. Romanovsky, L. Bengtsson, L. Brigham, M. Dyurgerov, J.C. Gascard, S. Gerland, R. Graversen, C. Haas, M. Karcher, P. Kuhry, J. Maslanik, H. Melling, W. Maslowski, J. Morison, D. Perovich, R. Przybylak, V. Rachold, I. Rigor, A. Shiklomanov, J. Stroeve, D. Walker, J. Walsh / Contribution No. 2952 from NOAA. Pacific Marine Environmental Laboratory. 2006. URL: https://www.pmel.noaa.gov/pubs/PDF/rich2952/ rich2952.pdf (дата обращения 15.05.2019).

9. Total ozone series at Arosa $(\mathrm{CH})$ : homogenization and data comparison / J. Staehelin, A. Renaud, J. Bader, R. McPeters, P. Viatte, B. Hoegge, V. Bugnion, M. Giroud, H. Schill // Journal Geophysics Research. 1998. vol.. D5. no. 103, pp. 5827-5841.

10. A physical reconstruction of cosmic ray intensity since 1610 I.G. Usoskin, K. Mursula, S.K. Solanki, M. Schussler, G.A. Kovaltsov // Journal Geophysics Research. - 2002. - V. 107 (A11). - P.1374-1380 DOI: 10.1029/2002JA009343. URL: http://cc.oulu.fi/ usoskin/personal/2002ja009343.pdf (дата обрашения 15.05.2019).

11. Алексеев В.И. Вейвлет-анализ динамики изменений явления Эль-Ниньо и его прогнозирование // Вестник Югорского государственного университета. - 2018. - Т. 3 (50). - С. 75-87.

12. Кремер Н.Ш. Математическая статистика. - М.: ЮРАЙТ, 2018. $-259 \mathrm{c}$.

13. Sidorenkov N.S. The interaction between Earth's rotation and geophysical processes. - Weinheim: WILEY-VCH Verlag GmbH and Co. KGaA, 2009. - 305 p.

14. Darwin G.H. On the precession of a viscous spheroid and on the remote history of the Earth // Proceedings of the Royal Society of London, 1879. vol. 170. pp. 447-530.

15. Darwin G.H. On the secular changes in the elements of the orbit of a satellite revolving about a tidally distorted planet // Proceedings of the Royal Society of London. - 1880. - V. 171. - P. 713-891
16. Syvorotkin V.L. Hydrogen degassing of the Earth: natural disasters and the biosphere // Man and the Geosphere / Ed. by I.V. Florinsky. - New York: Nova Science Pabl., 2010. - P. 307-347.

17. The Antarctic ozone depletion caused by Erebus volcano gas emissions / V.V. Zuev, N.E. Zueva, E.S. Savelieva, V.V. Gerasimov // Atmospheric Environment. - 2015. - V. 122. P. 393-399

18. Zuev V.V., Zueva N.E., Savelieva E.S. Temperature and ozone anomalies as indicators of volcanic soot in the stratosphere // Atmospheric and Oceanic Optics. - 2015. - V. 28. - № 1. P. $100-106$.

19. Volcanogenic nanosized carbon aerosol in the stratosphere / V.V. Zuev, N.E. Zueva, P.K. Koutsenogii, E.S. Savelieva // Chemical Sustaining Deviation. - 2014. - V. 22. - № 1. - P. 81-86.

20. Current problems of global change / S.P. Perov, B.H. Subbaraya, D. Offermann, I.L. Galkina, G.M. Kruchenitsky // Proc. of International Conference. Forecasting Monsoons from Days to Years. - Delhi, India, 21-22 March, 2001. - P. 164-166.

21. Dickey J.O. Earth rotation // Global Earth Physics: a handbook of physical constants American Geophysical Union / Ed. by T.J. Ahrens. - Washington: American Geophysical Union, 1995. P. $356-368$.

22. Severino G. The structure and evolution of the Sun. - 2017. 283 p. URL: https://www.twirpx.com/file/2367219 (дата обращения 15.05.2019).

23. Филиппов Б.П. Эруптивные процессы на Солнце. - М.: Изд-во физико-математической литературы. 2007. -216 с.

24. Сотникова Р.Т., Кашапова Л.К. Введение в физику Солнца. Иркутск: Изд-во Иркутского госуниверситета, 2012. - 195 с.

25. Кислов А.В., Суркова Г.В. Климатология. - М: ИНФРА, 2017. $-324 \mathrm{c}$

26. Тюпин В.Н. Динамика изменения рельефа поверхности Земли при коллизии литосферных плит // Научные ведомости. Серия: Естественные науки. - 2017. - Т. 43. - № 1. - С. 42-51.

27. Рогожин Е.А. Тектоническая позиция, геологические проявления очагов и афтершоковые процессы серии сильных землетрясений 2016-2017 гг. в центральной Италии // Геотектоника - 2017. - № 6. - С. 96-105.

28. Трифонов В.Г., Соколов С.Ю. Подлитосферные течения в мантии // Геотектоника. 2017. - № 6. - С. 3-17.

29. Тюпин В.Н. Взрывные и геомеханические процессы в трещиноватых напряженных горных массивах. - Белгород: ИД «Белгород», 2017.- 192 с.

30. Метелкин Д.В., Казанский А.Ю. Геотектоника и геодинамика: основы магнитотектоники. - М.: ЮРАЙТ. 2019. - 126 с.

31. Климов Г.К., Климова А.И. Науки о Земле. - М.: ИНФРА-М, 2017. $-390 \mathrm{c}$

Поступила 16.06.2020 г.

\section{Информация об авторе}

Алексеев В.И., доктор технических наук, профессор Института цифровой экономики Югорского государственного университета. 
UDC 517.9; 004; 551.58

\title{
STUDYING THE CHANGES IN GLOBAL CLIMATE USING WAVELET PHASE-FREQUENCY FUNCTIONS, PHASE-FREQUENCY AND PHASE-TEMPORAL CHARACTERISTICS OF HELOCOSMIC AND CLIMATIC VARIABLES. PART 2
}

\author{
Valery I. Alekseev, \\ v_alekseev@ugrasu.ru \\ Uygra State University, \\ 16, Chekhov street, Khanty-Mansiysk, 628012, Russia.
}

\begin{abstract}
The relevance of the research is caused by the need to establish the true reasons and patterns of global climate change on Earth. The aim of the research is to apply the method of calculating temporal wavelet phase-frequency functions, phase-frequency and phasetime characteristics developed using the continuous wavelet transformations in order to establish patterns of changes in the global climate, in particular, consistency of changes in solar variables with self-organized Pacific decade, North Atlantic and Southern/El Niño fluctuations, changes in the ozone layer in the stratosphere and warming in the Arctic zone of Russia, tectonic processes of the Earth.

Objects: time series of changes in solar and climatic variables, indices of North Atlantic and Southern/El Niño fluctuations, Pacific decadal fluctuations, series of Earth tectonic processes, series of changes in ozone standing in the stratosphere and air temperature in the Arctic. Methods: continuous direct wavelet transform of the source data using a complex wavelet with the calculation of time wavelet phasefrequency functions, phase-frequency and phase-time characteristics of variables, cluster analysis; assessment and analysis of densities of phase-time characteristics; evaluation and analysis of correlation coefficients between the phase-frequency and phase-time characteristics of variables in equal time intervals.

Results. Calculating the correlation matrices between the wavelet phase-frequency characteristics of the variables and constructing joint graphs of the phase-frequency and phase-time characteristics of these variables at specified time intervals, it was found that the changes in solar variables, solar activity, volcanic eruptions of the Earth, carbon dioxide and ozone concentrations in the atmosphere strata of the stratosphere, earthquakes, tsunamis and natural disasters, changes in the Earth's rotational speed and the duration of Earth's days belong to class-stand volatilities variables. These variabilities are caused by the changes in the distance of the Sun from the barycenter. The author established a close relationship between the oscillatory processes of heliocosmic variables, solar activity and volcanic processes on Earth, changes in atmospheric carbon dioxide concentration with self-organized processes of the North Atlantic, Pacific and Southern Oscillation (El Nino), associated with changes in the Earth's rotational speed and the duration of Earth days. It was substantiated that the growth of the Earth's volcanic activity in modern times leads to decrease in the ozone layer in the stratosphere, increase in solar radiation and surface temperature. In particular, these processes are strongly manifested in the Arctic zone of Russia. It is shown that the changes in surface temperature on Earth are caused by the changes in solar activity, the greenhouse effect, changes in ocean temperate and air temperature over land and ocean. The construction of images of temporal wavelet phase-frequency functions of phase-time characteristics of variables allows visualizing the history of changes of variables in time and in the phase-frequency domain and predicting these changes to a certain time horizon at characteristic frequencies.
\end{abstract}

\section{Key words:}

Global climate change, continuous direct wavelet transform, wavelet time phase-frequency function, wavelet phase-frequency and phase-time characteristics, correlation coefficients, ozone layer, warming in the Arctic, tectonic processes in the Earth's interior, oceanic self-organized oscillations.

\section{REFERENCES}

1. Sovremennye globalnye izmeneniya prirodnoy sredy [Modern global changes in the environment]. Eds. R.K. Klige, S.A. Lukyanova. Moscow, Nauchny mir Publ., 2006. Vol. 1, 696 p.

2. Sovremennye globalnye izmeneniya prirodnoy sredy [Modern global changes in the environment]. Eds. R.K. Klige, S.A. Lukyanova. Moscow, Nauchny mir Publ., 2006. Vol. 2, 776 p

3. Sovremennye globalnye izmeneniya prirodnoy sredy [Modern global changes in the environment]. T. 3. Faktory globalnykh izmeneni [Factors of global change] Eds. R.K. Klige, A.I. Khlystova. Moscow, Nauchny mir Publ., 2012. 444 p.

4. Kasimov N.S., Klige R.K. Vvedenie. Problemy globalnykh izmeneniy [Introduction. Problems of global changes]. Sovremennye globalnye izmeneniya prirodnoy sredy [Modern global changes in the natural environmenti]. T. 3. Faktory globalnykh izmeneniy [Factors of global change]. Moscow, Nauchny mir Publ, 2012. pp. $11-40$.

5. Smith T.M., Reynolds R.W. Extended Reconstruction of Global Sea Surface Temperatures Based on COADS database NOAA Journal Climate, 2003, vol. 16, pp. 1495-1510.

6. Guschina D.Yu. Anomalii klimata v tropikakh Tikhogo, Indiyskogo i Atlanticheskogo okeanov [Climate anomalies in the tropics of the Pacific, Indian and Atlantic oceans]. Sovremennye globalnye izmeneniya prirodnoy sredyi [Modern global changes in the natural environmenti]. Moscow, Nauchnyiy mir Publ, 2006. pp. 129-174.

7. Obridko V.N., Golyshev S.A., Levitin A.E. Secular and cycle variations of the IMF Bz component and some associated geophysical effects. SOLSPA 2001 Euroconference: Solar Cycle and Space Weather. Vico Equense, Italy, 24-29 September 2001. P. 404-407.

8. Richter-Menge J., Overland J., Proshutinsky A., Romanovsky V., Bengtsson L., Brigham L., Dyurgerov M., Gascard JC, Gerland S., Graversen R. Haas C ., Karcher M., Kuhry P., Maslanik J., Melling H., Maslowski W., Morison J., Perovich D., Przybylak R., Rachold V., Rigor I., Shiklomanov A., Stroeve J., Walker D., Walsh J. State of Arctic Report. Contribution No. 2952 from NOAA. Pacific Marine Environmental Laboratory. 2006. Available at: https://www.pmel.noaa.gov/pubs/PDF/rich2952/ rich2952.pdf (accessed 05 May 2019).

9. Staehelin J., Renaud A., Bader J., McPeters R., Viatte P, Hoegge B., Bugnion V., Giroud M., Schill H. Total ozone series at Arosa (CH): homogenization and data comparison. Journal Geophysics Research, 1998, vol. D5, no. 103, pp. 5827-5841.

10. Usoskin I. G., Mursula K., Solanki S.K., Schussler M., Kovaltsov G.A. A physical reconstruction of cosmic ray intensity since 1610 . Journal Geophysics Research, 2002, vol. 107 (A11), pp. 1374-1380. DOI: 10.1029/2002JA009343.Available at: http://cc.oulu.fi/ usoskin/personal/2002ja009343.pdf (accessed 05 May 2019). 
11. Alekseev V.I. Weyvlet-analiz dinamiki izmeneniy yavlenia ElNino i ego prognozirovanie [Wavelet analysis of the dynamics of changes in the El Nino phenomenon and its forecasting]. Vestnik Yugorskogo gosudarstvennogo universiteta, 2018, vol. 3 (50), pp. 75-87.

12. Kremer N.Sh. Matematicheskaya statistika [Mathematical statistics]. Moscow, Yurayt Publ., 2018. 259 p.

13. Sidorenkov N.S. The interaction between Earth's rotation and geophysical processes. Weinheim, WILEY-VCH Verlag GmbH and Co. KGaA, 2009. 305 p.

14. Darwin G.H. On the precession of a viscous spheroid and on the remote history of the Earth. Proceedings of the Royal Society of London, 1879, vol. 170, pp. 447-530.

15. Darwin G.H. On the secular changes in the elements of the orbit of a satellite revolving about a tidally distorted planet. Proceedings of the Royal Society of London, 1880, vol. 171, pp. 713-891.

16. Syvorotkin V.L. Hydrogen degassing of the Earth: Natural disasters and the biosphere. Man and the Geosphere. Ed. by I.V. Florinsky. New York, Nova Science Publ., 2010. pp. 307-347.

17. Zuev V.V., Zueva N.E., Savelieva E.S., Gerasimov V.V. The Antarctic ozone depletion caused by Erebus volcano gas emissions. Atmospheric Environment, 2015, vol. 122, pp. 393-399.

18. Zuev V.V., Zueva N.E., Savelieva E.S. Temperature and ozone anomalies as indicators of volcanic soot in the stratosphere Atmospheric and Oceanic Optics, 2015, vol. 28, no. 1, pp. 100-106.

19. Zuev V.V., Zueva N.E., KoutsenogiiP.K., Savelieva E.S Volcanogenic nanosized carbon aerosol in the stratosphere. Chemical Sustaining Deviation, 2014, vol. 22, no. 1, pp. 81-86.

20. Perov S.P., Subbaraya B.H., Offermann D., Galkina I.L., Kruchenitsky G.M. Current problems of global change. Proc. of International Conference. Forecasting Monsoons from Days to Years. Delhi, India, March 21-22, 2001. pp. 164-166.

21. Dickey J.O. Earth rotation. Ed. by T.J. Ahrens. Global Earth Physics: a handbook of Physical Constants American Geophysical Union, Washington, 1995. pp. 356-368.
22. Severino G. The structure and evolution of the Sun. 2017. 283 p. Available at: https://www.twirpx.com/file/2367219 (accessed 05 May 2019)

23. Filippov B.P. Eruptivnye protsessy na Solntse [Eruptive processes in the Sun]. Moscow, Izdatelstvovo fiziko-matematicheskoy literatury, 2007. $216 \mathrm{p}$.

24. Sotnikova R.T., Kashapova L.K. Vvedenie v fiziku Solntsa [Introduction to the physics of the sun]. Irkutsk, Irkutsk State University Publ., 2012. 195 p.

25. Kislov A.V., Surkova G.V. Klimatologiya [Climatology]. Moscow, INFRA Publ., 2017. 324 p.

26. Tyupin V.N. Dinamika izmeneniya relefa poverkhnosti Zemli pri kollizii litosfernykh plit [The dynamics of changes in the relief of the Earth's surface during a collision of lithospheric plates]. Nauchnye vedomosti. Seriya: Estestvennyie nauki, 2017, vol. 43, no. 1 , pp. $42-51$.

27. Rogozhin E.A. Tektonicheskaya pozitsiya, geologicheskie proyavleniya ochagov i aftershokovye protsessy serii silnykh zemletryaseniy 2016-2017 gg. v tsentralnoy Italii [The tectonic position, the geological manifestations of the foci and the aftershock processes of the series of strong earthquakes of 20162017 in central Italy]. Geotektonika, 2017, no. 6, pp. 96-105.

28. Trifonov V.G., Sokolov S.Yu. Podlitosfernye techeniya v mantii [Sublithospheric currents in the mantle]. Geotektonika, 2017, no. 6 , pp. 3-17.

29. Tyupin V.N. Vzryvnye $i$ geomekhanicheskie protsessy $v$ treshchinovatykh napryazhennykh gornykh massivakh [Explosive and geomechanical processes in fractured stressed mountain ranges]. Belgorod, ID Belgorod Publ., 2017. 192 p.

30. Metelkin D.V., Kazanskiy A.Yu. Geotektonika $i$ geodinamika: osnovy magnitotektoniki [Geotectonics and geodynamics: the basics of magnetotectonics]. Moscow, Yurayt Publ., 2019. 126 p.

31. Klimov G.K., Klimova A.I. Nauki o Zemle [Earth sciences]. Moscow, INFRA Publ., 2017. 390 p

Received: 16 June 2020.

Information about author

Alekseev V.I., Dr. Sc., professor, Uygra State University. 